\title{
БРИТАНИЯ: РАСКОЛ В ВЕДУЩИХ ПАРТИЯХ НА ФОНЕ БРЕКЗИТА
}

\begin{abstract}
Аннотация. 14 февраля 2019 г. британский парламент отклонил резолючию правительства, но Т. Мэй продолжила переговоры с Брюсселем об изменениях в Соглашении с Европейским союзом. Разногласия в обеих ведущчих партиях обострились, вылившись в раскол, создание новых партий и движений на фоне недоверия британщев к политическим лидерам и партиям, раскола в обществе по вариантам брекзита. Политический кризис обостряется.

Ключевые слова: брекзит, Тереза Мэй, Соглашение о выходе Британии из ЕС, британский парламент, Европейский союз, Лейбористская партия, Консервативная партия, Независимая группа.
\end{abstract}

14 февраля 2019 г. в британском парламенте прошло очередное голосование по курсу правительства в отношении брекзита, поскольку Европейский союз снова отказался вносить изменения в Соглашение в выходе, касающиеся режима ирландской границы. Проект резолюции правительства гласил: Палата общин приветствует заявление премьер-министра от 12 февраля 2019 г., поддерживает подход к выходу из ЕС, выраженный Палатой 29 января, и отмечает, что Великобритания и Евросоюз продолжают обсуждать режим ирландской границы.

Т. Мэй постоянно отказывается исключить вариант выхода «без сделки», заявив 12 февраля, что намерена добиваться от Брюсселя юридически обязывающих изменений в Соглашении (поправка Брейди) ${ }^{1}$, напомнив депутатам, что они проголосовали и за то, чтобы исключить выход «без сделки». Действительно, 29 января парламент принял не только поправку Брейди, но и противоречащую ей поправку Спелман-Дроми, направленную против выхода без сделки.

Резолюцию Т. Мэй депутаты отклонили (303:258), поскольку заднескамеечники-тори из стана брекзитёров приняли коллективное решение воздержаться (67 депутатов), опасаясь, что премьер-министр стремится отказаться от выхода без сделки, о чём свидетельствовала нейтральная по сути резолюция правительства (опора на обе поправки).

Не проголосовала за резолюцию правительства и часть тори-бремейнеров. Более того, пять брекзитёров и один бремейнер от тори даже проголосовали за поправку лейбористов,

\footnotetext{
(C) Ананьева Елена Владимировна - кандидат философских наук, ведущий научный сотрудник, руководитель Центра британских исследований ИЕ РАН. Адрес: 125009, Россия, Москва, ул. Моховая, д. 11, стр. 3. E-mail: e-ananieva@ yandex.ru.
}

DOI: http://dx.doi.org/10.15211/vestnikieran120191723

${ }^{1}$ Поправка предусматривает соглашение о свободной торговле с ЕС и технические средства, способные обеспечить прозрачную ирландскую границу. В случае отказа Брюсселя предполагается продлить переходный период до конца 2021 г., чтобы согласовать «упорядоченный» выход Британии из ЕС на основе правил ВТО. Однако ЕС заявлял, что не станет пересматривать Соглашение или продлевать переходный период лишь для того, чтобы Британия вышла из ЕС без сделки. См. Ананьева Е.В. Сработает ли «компромисс Молтхауса»? Международная жизнь, 2019. URL: https://interaffairs.ru/news/show/21549. 
пусть и проигрышную. Бремейнеры объединяются, внося межпартийные поправки к резолюциям парламента (поправка Спелман-Дроми, Субри-Амунны), за которые голосуют сквозь линии партийного размежевания.

Голосование 14 февраля 2019 г. носило символический характер, не имело юридической силы для правительства, но подрывало позиции Т. Мэй на переговорах с Брюсселем.

Масла в огонь подлило заявление премьер-министра Нидерландов М. Рютте о том, что Британия «слишком мала», чтобы иметь вес на мировой арене, что брекзит ослабит её экономику, и что она останется одна в Атлантическом океане, не входя ни в США, ни в ЕС ${ }^{1}$. Брюссель, по мнению обозревателей, пытается заставить её принять поддержку Дж. Корбина, заявившего, что его партия проголосует за более тесные связи с Евросоюзом (включая таможенный союз), что вызовет негодование брекзитёров.

20 февраля Т. Мэй направилась в Брюссель, отказавшись от договорённости брекзитёров и бремейнеров своей партии («компромисса Молтхауса») в формулировке поправки Брейди, понизив планку до юридической гарантии временного пребывания Британии в Таможенном союзе ЕС. Согласится ли Брюссель дать такую юридическую гарантию и устроит ли она брекзитёров-тори и ольстерских юнионистов?

Следующее голосование в парламенте должно состояться 27 февраля и может стать кульминацией баталий по брекзиту. Т. Мэй заявила, что если к тому времени не представит парламенту пересмотренное Соглашение, то предложит новый проект резолюции. Однако она может снова отложить голосование - до 21 марта, на которое назначен саммит ЕС.

Стало известно, что отсрочка нужна Т. Мэй, чтобы вынудить брекзитёров-тори проголосовать за уже согласованное с Брюсселем и проваленное парламентом 15 января соглашение, поставив перед выбором: или Соглашение, или продление членства Британии в ЕС на длительный период ${ }^{2}$. Последнее может привести к отказу от брекзита вообще, чего опасаются брекзитёры.

Дальнейшая отсрочка спровоцирует отставки членов правительства, попытку парламента взять контроль над брекзитом в свои руки (межпартийная поправка бремейнеров Иветт Купер и О. Летвина), позволяющую депутатам выбрать между выходом без сделки и продлением действия ст. 50 Лиссабонского договора. Бремейнеры от тори, скорее всего, поддержат поправку Купер. Не исключены попытки Т. Мэй договориться с частью лейбористов, чтобы компенсировать выпадающие голоса брекзитёров-тори.

\section{Брекзитёры и бремейнеры объединяются сквозь линии партийного размежевания}

В обеих ведущих партиях раскол проходит уже не столько по линии политического спектра (левое-правое крыло), сколько по отношению к брекзиту. Соответственно, в обеих партиях есть депутаты-«перебежчики», голосующие против курса своей партии. Центристы и умеренные в обеих партиях недовольны сдвигом своих партий к полюсам - левому в ЛПВ и правому в Консервативной партии. Мажоритарная избирательная система удерживает партии от расколов, заставляя их быть «зонтичными». Однако разногласия оказались настолько остры, что раскол произошёл в обеих партиях, вопреки Б. Дизраэли: «К черту принципы! Оставаться в партии» (Damn your principles! Stick to your party).

\section{Раскол в Лейбористской партии}

\footnotetext{
${ }^{1}$ Government defeated on Brexit next steps motion. 15.02.2019. URL: https://www.parliament.uk/business/news/2019/ february/house-of-commons-debates-new-motion-on-brexit-next-steps/ ${ }^{2}$ Ibid.
} 
18 февраля семеро депутатов от Лейбористской партии Великобритании (ЛПВ) объявили о выходе из партии, создав Независимую группу (Independent Group) в парламенте. Недовольство в парламентской фракции Дж. Корбином, «слишком левым» для центристов и правых, уже прорывалось. После референдума о членстве Британии в ЕС (2016 г.) фракция объявила ему недоверие за «вялую» кампанию в пользу членства, спровоцировав вторые за год выборы лидера партии. Корбин выиграл их с ещё большим преимуществом, чем в 2015 г. $^{1}$ Досрочные парламентские выборы 2017 г. прошли для партии удачно (+30 мест), и фракция встретила его аплодисментами. Однако трения не прекратились: правое крыло и центристы обвиняют Корбина за позиции в вопросах безопасности, за отношение к НАТО, мнение по «делу Скрипалей» и модернизации ядерной системы «Трайдент».

Конкретным поводом послужила позиция Корбина по брекзиту: нежелание поддержать новый референдум по отношениям с ЕС. Однако столь же жёсткую позицию, но уже против референдума занимают депутаты-лейбористы от округов, где проголосовали за выход из Европейского союза. Генеральный секретарь профсоюза «Юнайт» Л. МакКласки, соратник Корбина, заявил, что «остановить брекзит - не лучший вариант для страны» ${ }^{2}$.

Независимая группа не объявляет себя политической партией, хотя может эволюционировать в этом направлении к концу года, и готова принять в свои ряды недовольных из партии тори, что и произошло 20 февраля.

\section{Раскол в Консервативной партии}

Лидером тори недовольны оба крыла партии - Мэй не желает сделать выбор. Цель Мэй - удержать партию от раскола, и многие аналитики сходятся в том, что она больше боится брекзитёров ${ }^{3}$.

В парламентской фракции Консервативной партии около 80 депутатов брекзитёров составляют Группу европейских исследований во главе с Дж. Рис-Моггом. Они более сплочены организационно и целеустремлённее, чем однопартийцы бремейнеры. «Армагеддон для тори» наступит, если брекзитёры потребуют выхода без сделки и Т. Мэй им откажет; «невозможно побороть страсть к мученичеству аргументами технического характера вроде угрозы очередей из грузовиков в Дувре - эти извращённые фантазии можно устранить лишь действительным кризисом», а потому бремейнеры проиграли ещё с референдума, писала «The Guardian» ${ }^{4}$.

Бремейнеры утверждают, что если выход без сделки не будет исключён, то около десяти министров и замминистров могут подать в отставку. Бремейнеры опасаются, что откладывая решающее голосование, Т. Мэй неизбежно «по умолчанию» спровоцирует выход без сделки. Более того, они предупреждают, что партия перенимает идеологию Партии независимости Соединённого Королевства (ПНСК), а инфильтрация брекзитёров из ПНСК в местные отделения партии приведёт к негативным последствиям для бремейнеров при отборе кандидатов в депутаты от тори на следующих парламентских выборах.

\footnotetext{
${ }^{1}$ Ананьева Е.В. Исчезающий центр. Международная жизнь. №10. 2016. URL: https://interaffairs.ru/jauthor/mate rial/1749.

${ }_{2}^{2}$ Labour MPs warn Corbyn: back a second referendum or we quit. URL: https://www.theguardian.com/politics/ 2019/feb/13/labour-mp-submits-plan-for-referendum-on-brexit-deal.

${ }^{3}$ Waugh P. Why A No-Deal Brexit Is Now Theresa May's Fallback Plan To Save Her Party - And Herself. URL: https://guce.oath.com/collectConsent?sessionId=3_cc-session_7b45ee7f-4c42-4c5e-b7b3-e09ac4d33fac\&lang=\&inline =false; Peston R. Why I think a no-deal Brexit is now the most likely outcome. URL: https://blogs.spectator.co.uk/ 2019/02/why-i-think-a-no-deal-brexit-is-now-the-most-likely-outcome/blogs.spectator.co.uk.

${ }^{4}$ Malik N. Britain needs a day of reckoning. Brexit will provide it. URL: https://www.theguardian.com/commentisfree/ 2019/feb/18/britain-brexit.
} 
Брекзитёры не поддаются уговорам смягчить позиции, и бремейнеры говорят, что брекзитёрам «некуда идти» в парламенте (нет иной политической силы, к которой они могли бы примкнуть), а бремейнерам «есть куда пойти», то есть им откроют двери партии, поддерживающие сохранение тесных связей Британии в Евросоюзе. Соответственно, лидеру тори следовало бы больше прислушиваться к бремейнерам, которые в противном случае могут спровоцировать переформатирование расклада политических сил. Бремейнеры воплотили свою угрозу: 20 февраля три депутата вышли из партии, присоединившись к Независимой группе ${ }^{\mathbf{1}}$.

\section{Новые партии и движения}

В Вестминстере давно шли переговоры о создании новой центристской партии бремейнеров из состава лейбористов и консерваторов. Если первые, прежде всего, стремятся провести новый референдум по Европейскому союзу, то вторые - исключить выход без сделки, а вместе участвуют в движении «Народное голосование» (People's Vote) - за новый референдум. Циркулируют мнения, что новую партию назовут «Реформистская партия» (Reformist party) $)^{2}$ при организационной поддержке на общенациональном и местном уровне со стороны ПЛД. Ожидают, что лидер ПЛД В. Кейбл освободит пост после местных выборов в мае, уступив кандидату от нового движения, а сама партия готова к избирательным пактам, слияниям и альянсам, поддержке независимых кандидатов.

Что касается брекзитёров, то бывший лидер ПНСК Н. Фарадж создал новую «Партию брекзит» (Brexit Party), в которую готовы вступить 100 тыс. человек (численность партии тори - 124 тыс.). Финансист и бывший донор Консервативной партии Дж. Хоскинг создал партию «Брекзит экспресс» (Brexit Express) ${ }^{3}$. Они рассчитывают на приток брекзитёров от тори и готовятся к действиям в случае отсрочки брекзита (и, соответственно, участия Британии в выборах в Европарламент), второго референдума или досрочных выборов.

Межпартийная группа брекзитёров (в том числе бывший лидер тори Й. Данкан Смит, лейбористка Кейт Хоуи, Н. Фарадж), готовясь к новому референдуму, проводит акции под лозунгом «Выйти значит выйти» (Leave Means Leave).

\section{Опросы общественного мнения}

Социологические агентства отмечают потребность британцев в новой политической партии. По опросу в середине февраля, различие в поддержке обеих ведущих партий остаётся в рамках статистической погрешности при общем разочаровании в них: $41 \%$ респондентов считают обе партии радикальными, а 42\% полагают, что ни одна из них не имеет чёткой позиции; 40\% выступают за создание новой политической партии, а 59\% готовы голосовать за новую центристскую партию ${ }^{4}$.

\footnotetext{
${ }^{1}$ Местные отделения партий могут выразить недоверие «раскольникам» и не выставлять их кандидатуры на следующих парламентских выборах (deselection). В партии тори проводит ежегодные (до конца марта) собрания местных отделений, на которых может решаться вопрос о выражении недоверия депутату. Не только «раскольников», но и бремейнеров-тори могут забаллотировать в качестве кандидатов. Проблема заключается в подотчётности депутата: чьи интересы должны представлять депутаты - местного отделения партии или избирателей округа, которые обычно занимают центристские позиции. В ЛПВ могут ввести обязательную процедуру номинации кандидата, чтобы исключить «пожизненный наём» (ныне кандидатуру действующего депутата вновь подвергают отбору по требованию 33\% местных отделений партии и аффилированных профсоюзов в избирательном округе).

2 Labour and Tory MPs in talks over setting up new centrist party. URL: https://www.theguardian.com/politics/ 2019/feb/15/uk-mps-intense-talks-setting-up-new-centrist-party-labour.

${ }^{3}$ No-dealers dig in for a fresh battle amid fears of Tory split. URL: https://www.theguardian.com/politics/2019/feb/17/ no-deal-brexiters-tory-split-conservative-multimillionaire-donor-new-party.

${ }^{4}$ UK Polling report. 07.02.2019; 11.02.2019. URL: http://ukpollingreport.co.uk/
}

Научно-аналитический вестник ИЕ РАН, 2019, №1 
Более того, только Независимая группа сформировалась (не имея ни программы, ни регистрации в качестве политической партии), как она оказалась популярнее ПЛД и ПНСК (10:9:6), привлекая голоса сторонников (по убывающей) лейбористов, консерваторов, абсентеистов и ПЛД ${ }^{1}$. Согласно опросу Yougov (ещё до присоединения к ней троих тори), данные ещё благоприятнее: $14 \%$ - готовность голосовать за неё на выборах, но отберёт она голоса (по убывающей) у консерваторов, лейбористов, ПЛД 2 . Какова бы ни была судьба нового политического объединения, его моментальная популярность свидетельствует о неприятии избирателями основных партий.

Интересен тот феномен, что при непопулярности Т. Мэй (-25\%) рейтинг лидера оппозиции Дж. Корбина ещё ниже $(-40 \%)^{3}$. По опросу Ipsos-Mori, Дж. Корбин - самый непопулярный лидер оппозиции за 40 лет $(-55 \%)^{4}$. ЛПВ считают расколотой по вопросу брекзита две трети респондентов среди сторонников лейбористов и в целом по стране (неизменная цифра с декабря 2016 г.). Ещё больше британцев считают расколотой партию тори (76\% по сравнению 67\% в декабре 2016 г.), но цифра выше (86\%) среди её сторонников. В вопросе, чьи интересы по брекзиту отстаивают лидеры партий (личные, своей партии, страны), британцы отдают предпочтение премьер-министру: Т. Мэй (25:33:36), Дж. Корбин (47:27:18). Велико и недоверие к депутатам: лейбористы (38:30:18), консерваторы (47\% - личные) ${ }^{5}$.

По-прежнему не сформировалось большинство по вариантам брекзита в обществе. Несколько менее половины респондентов считает Соглашение с ЕС «плохим», лишь 51\% сторонников консерваторов поддерживают его. Глубокий раскол очевиден по варианту дальнейших действий: $42 \%$ - отложить выход и провести второй референдум, такая же доля - выйти без сделки. Однако в случае референдума $46 \%$ проголосуют за членство в Европейском союзе, $35 \%$ - за выход на условиях Соглашения Т. Мэй. Британия выйдет со сделкой (21\%), без сделки (36\%), останется в ЕС (24\%).

Между тем министр обороны Г. Уильямсон выступает с весьма агрессивными речами, утверждая о мировой мощи Великобритании ${ }^{6}$. Обозреватели вписывают состояние умов в общий контекст представлений британцев о своей стране: «Страна парализована, поляризована, разваливается, но заблуждается насчёт своего глобального статуса» ${ }^{7}$.

\section{Выводы:}

1. Откладывая решающее голосование в парламенте, правительство Т. Мэй продолжает добиваться юридически обязательных изменений в Соглашении о выходе Британии из Европейского союза, чтобы умиротворить брекзитёров в партии тори, недооценив недовольство

\footnotetext{
${ }^{1}$ Independent Group «more popular than Lib Dems»: Sky Data poll. URL: https://news.sky.com/story/independentgroup-third-most-popular-party-sky-data-poll-11642205. 19.02.2019.

14\% would vote for The Independent Group. 20.02.2019. URL: https://yougov.co.uk/topics/politics/articles-reports/ 2019/02/20/14-would-vote-independent-group.

${ }^{3}$ Labour pulls level with Tories in latest opinion poll. URL: https://www.theguardian.com/politics/2019/feb/16/labourpulls-level-with-tories-in-latest-opinion-poll.

${ }^{4}$ Opposition Party Leaders: Ipsos MORI Satisfaction ratings 1977-2019. URL: https://www.ipsos.com/ipsos-mori/en-uk /opposition-party-leaders-ipsos-mori-satisfaction-ratings-1977-2019; Confidence in Theresa May to get a good Brexit deal falls. 07.02.2019. URL: https://www.ipsos.com/ipsos-mori/en-uk/confidence-theresa-may-get-good-brexit-deal-falls.

5 Jeremy Corbyn's satisfaction ratings fall to historic low. URL: https://www.ipsos.com/ipsos-mori/en-uk/jeremycorbyns-satisfaction-ratings-fall-historic-low. 08.02.2019.

${ }^{6}$ Gavin Williamson Speech. Defence in Global Britain. 11.02.2019. URL: https://www.gov.uk/government/speeches/ defence-in-global-britain; Gavin Williamson Speech. The Munich Security Conference. 15.02.2019. URL: https://www. gov.uk/government/speeches/the-munich-security-conference.

Malik N. Britain needs a day of reckoning. Brexit will provide it. URL: https://www.theguardian.com/commentisfree/ 2019/feb/18/britain-brexit.
} 
бремейнеров.

2. Неспособность парламента склониться к какому-либо варианту действий отражает глубокие разногласия в партиях и в обществе в связи с брекзитом.

3. Острые разногласия по брекзиту приняли организационную форму раскола в Лейбористской и Консервативной партиях; брекзитёры и бремейнеры создают свои политические объединения и партии. Создание Независимой группы из членов соперничающих ЛПВ и тори - беспрецедентное событие: партийно-политическая система Британии вступает в процесс переформатирования.

4. Британцы глубоко разочарованы в ведущих партиях и их лидерах, что свидетельствует об отчуждении общества от власти. Политический кризис обостряется.

\section{Список литературы}

Ананьева Е.В. Сработает ли «компромисс Молтхауса»? Международная жизнь. 2019. URL: https://interaffairs.ru/news/show/21549.

Ананьева Е.В. Исчезающий центр. Международная жизнь. №10, 2016. URL: https://inter affairs.ru/jauthor/material/1749.

\section{References}

Anan'va E.V. Will the Malthouse Compromise Work? Mezhdunarodnaja zhizn'. 2019. URL: https://interaffairs.ru/news/show/21549.

Anan'eva E.V. The Centre Is Melting Away. Mezhdunarodnaja zhizn’. №10, 2016. URL: https://interaffairs.ru/jauthor/material/1749.

Government defeated on Brexit next steps motion. 15.02.2019. URL: https://www. parliament. uk/business/news/2019/february/house-of-commons-debates-new-motion-on-brexit-next-steps/

Confidence in Theresa May to get a good Brexit deal falls. 07.02.2019. URL: https://www.ipsos.com/ipsos-mori/en-uk/confidence-theresa-may-get-good-brexit-deal-falls.

Gavin Williamson Speech. Defence in Global Britain. 11.02.2019. URL: https://www.gov.uk/ government/speeches/defence-in-global-britain.

Gavin Williamson Speech. The Munich Security Conference. 15.02.2019. URL: https://www. gov.uk/government/speeches/the-munich-security-conference.

Independent Group «more popular than Lib Dems»: Sky Data poll. URL: https://news.sky.com/ story/independent-group-third-most-popular-party-sky-data-poll-11642205.

Jeremy Corbyn's satisfaction ratings fall to historic low. URL: https://www.ipsos.com/ipsosmori/en-uk/jeremy-corbyns-satisfaction-ratings-fall-historic-low. 08.02.2019.

Labour pulls level with Tories in latest opinion poll. URL: https://www.theguardian.com/ politics/2019/feb/16/labour-pulls-level-with-tories-in-latest-opinion-poll.

Malik N. Britain needs a day of reckoning. Brexit will provide it. URL: https://www.theguardi an.com/commentisfree/2019/feb/18/britain-brexit.

Opposition Party Leaders: Ipsos MORI Satisfaction ratings 1977-2019. URL: https://www.ips os.com/ipsos-mori/en-uk/opposition-party-leaders-ipsos-mori-satisfaction-ratings-1977-2019.

UK Polling report. 07.02.2019; 11.02.2019. URL: http://ukpollingreport.co.uk/

Yougov. $14 \%$ would vote for The Independent Group. 20.02.2019. URL: https://yougov.co.uk/topics/politics/articles-reports/2019/02/20/14-would-vote-independent-group

\section{UK Leading Parties Split on the Background of Brexit}

Научно-аналитический вестник ИЕ РАН, 2019, №1 
Author. Elena Ananieva, Candidate of Sciences (Philosophy), Head of Centre for UK Studies, Institute of Europe, Russian Academy of Sciences. Address: 11-3, Mokhovaya str., Moscow, Russia, 125009. E-mail: e-ananieva@yandex.ru.

Abstract. The UK parliament defeated the government motion on $14^{\text {th }}$ February 2019. Still the PM resumed talks with Brussels on the backstop on the brexiteer Brady amendment adopted on January, 29. Tensions in the leading parties grew into a split in both of them. New groups, parties and movements are created as the British public is divided on Brexit and deeply disappointed with politics.

Key words: Brexit, Theresa May, UK-EU Withdrawal Agreement, UK parliament, European Union, Labour Party, Conservative Party, Independent Group, political crisis.

DOI: http://dx.doi.org/10.15211/vestnikieran120191723 